\title{
IN VITRO EFFECTS OF VARIOUS PROBIOTIC PRODUCTS ON GROWTH AND BIOFILM FORMATION OF CLINICAL UPEC STRAINS
}

\author{
Defne GÜMÜŞ ${ }^{1 *}$, Fatma KALAYCI YÜKSEK, ${ }^{1}$ Merve BILLGİN ${ }^{2}$, Firdevs Deniz CAMADAN ${ }^{3}$ \\ Mine ANĞ KÜÇÜKER ${ }^{1}$
}

İstanbul Yeni Yüzy1l University ${ }^{1}$ Department of Medical Microbiology, Faculty of Medicine,
${ }^{2}$ Department of Pharmaceutical Microbiology, Faculty of Pharmacy
${ }^{3}$ Department of Molecular Biology and Genetics, Faculty of Arts and Science, Istanbul, Turkey

*Correspondence:

Defne GÜMÜŞ

defne.gumus@yeniyuzyil.edu.tr

Received: 02 January 2020; Accepted: 05 February 2020; Published: 30 June 2020

\begin{abstract}
Uropathogenic Escherichia coli (UPEC) is the most prevalent pathogen causing urinary tract infections (UTIs). UPECs have various virulence factors such as adhesins, biofilm forming and toxin producing etc., to survive in urinary tract. Under certain circumstances probiotics are preferred for prevention and treatment of UTIs. In this study, we aimed to investigate the in-vitro effects of four different Lactobacillus spp. cell-free supernatants on growth and biofilm formation inhibition in clinically isolated UPEC strains. Growths of 50 UPEC strains were determined in 96-well microplate and measured in a spectrophotometer after four hours incubation at $37^{\circ} \mathrm{C}$. Biofilm formation was detected by crystal violet staining method on three UPEC strains. Statistical analysis of growth and biofilm formation experiments were performed by Kruskal-Wallis and one-way ANOVA Tukey's multiple-comparison tests, respectively. All tested cell-free supernatans of lactobacilli inhibited growths $(p<0.0001)$ and biofilm formation $(p<0.05)$ of UPECs. All results were found to be statistically significant. As a conclusion, our findings supported previous studies which reported the high efficiency of these four Lactobacillus spp. in the prevention of UTIs.
\end{abstract}

Keywords: Lactobacillus, growth, biofilm formation, UPEC, probiotics.

\section{Introduction}

Uropathogenic Escherichia coli (UPEC) have various virulence factors such as fimbrial adhesins, biofilm formation, siderophore, toxins, cytotoxic necrotizing factor-1, bacteriocins, endonuclease activity, and outer membrane protease. They are known as the leading pathogens causing urinary tract infections (UTI) (Mandal, 2001; Ruiz et al., 2002; Miyazaki et al., 2002; Bower et al., 2005; Sabaté et al., 2006; Yamamoto, 2007;
Uzun et al., 2015). Biofilm formation capacity of UPEC strains is also an important advantage for the persistence and recurrence in infections caused by them. Besides, biofilm formation protects from host immunity and antimicrobial components (Freestone, 2013). Urinary tract infections (UTI) are seen about $40 \%$ in women, $12 \%$ in men for their life time and often recur within 6 to 12 months nearly in $25 \%$ of infected women (Kulkarni et al., 2009; Sivick 
and Mobley, 2010; Li et al., 2010). Recurrent infections could be due to unsuccessful treatments which is related to antibiotic resistance and invasive infections (Hunstad and Justice, 2010; Andersen et al., 2012). Therefore some alternative strategies such as probiotics are useful and more cost effective for their treatment (Geerlings et al., 2014; Beerepoot et al., 2012; Delley et al., 2015; Lee et al., 2016).

Probiotics are known as live microorganisms which beneficially regulate host health (FAO/WHO, 2001). It is well known that the beneficial effects of lactobacilli depend on secreting several strong antimicrobial compounds such as organic acids, benzoic acid, acetic acid, formic acid different types of bacteriocins, bacteriocin-like inhibitory substances and hydrogen peroxide (Lash et al., 2005; Kim and Kim, 2009).

Lactobacillus spp. and Bifidobacterium spp. are the most administered bacteria, especially for prevention and control of oral, gastrointestinal and urogenital system diseases (Saavedra 2000; Tomas et al., 2003; Morelli et al., 2004; Servin, 2004; Morais, 2006; SegarraNewnham, 2007; Guarino et al., 2009; Miyazaki et al., 2010; Guandalini, 2011; Wagner and Johnson, 2012; Behnsen et al., 2013; Turroni et al., 2014; Wu et al., 2015). For example, Lactobacillus plantarum, Lactobacillus reuteri, Lactobacillus rhamnosus and Lactobacillus acidophilus are known to inhibit biofilm formation of pathogens (Miyazaki et al., 2010; Wagner and Johnson, 2012; Wu et al., 2015). Cadieux et al., (2009) mentioned the antagonist effects of urogenital lactobacilli for UPECs and explained that their lethal effects do not occur only directly, but they can provide stress conditions for bacteria.

In the present study, we aimed to evaluate the in-vitro effects of four different lactobacilli cell-free supernatants on growth and biofilm formation in UPEC strains isolated from UTI patients.

\section{Materials and Methods}

\section{Bacterial strains, media and culture conditions}

In the present study cell-free supernatants of Lactobacillus rhamnosus ATCC 53103, Lactobacillus fermentum ATCC 9338, Lactobacillus acidophilus ATCC 314, and Lactobacillus plantarum ATCC 14917 were tested for their effects on growth and biofilm formation in UPECs. They were chosen according to their high usage in commercial probiotics (Karska-Wysocki, 2010; Nigam et al., 2012); therefore we prepared cell-free supernatants. All strains were stored in $-80^{\circ} \mathrm{C}$ prior to the experiments. De Man, Rogosa and Sharpe (MRS) broth and (MRS) agar (Conda, Spain) were used for isolation of all lactobacilli. Cultures were performed in anaerobic atmosphere $\left(10 \% \mathrm{H}_{2}, 5 \% \mathrm{CO}_{2}\right.$ and $85 \% \mathrm{~N}_{2}$ ) at $37^{\circ} \mathrm{C}$ for 48 hours. 50 UPEC strains from our culture collection were included in the present study; they were previously isolated from symptomatic, acute, uncomplicated UTI patients and they were proven for their pathogenic abilities (Uzun et al., 2015). Bacteria were kept in $-80^{\circ} \mathrm{C}$ and revived after 10 years via inoculating into Tryptic Soy Broth (TSB) and Tryptic Soy Agar (TSA). Overnight cultures of UPECs and all lactobacilli were prepared by inoculation of single colonies into TSB and MRS broth, respectively. The overnight cultures of each Lactobacillus strains were centrifuged at $4000 \mathrm{rpm}$ for 30 minutes at $4{ }^{\circ} \mathrm{C}$; strains and the supernatants were collected then filtered by using $0.2 \mu \mathrm{m}$ filter.

\section{Effects of cell-free supernatants of}

\section{Lactobacillus spp. on growth of UPECs}

Initial bacterial concentrations of UPECs were arranged to $10^{7} \mathrm{CFU} / \mathrm{mL}$. UPEC strains were cultured into TSB alone (as control) or TSB supplemented with different supernatants of Lactobacillus $(100 \mu \mathrm{L}$ cell-free supernatants $+80 \mu \mathrm{L} \mathrm{TSB}+20 \mu \mathrm{L}$ bacteria) and 
incubated at $37^{\circ} \mathrm{C}$. Growths were determined by measuring the changes via spectrophotometer in absorbance (OD) at 600 $\mathrm{nm}$ in four hours period. The samples were tested in duplicate and each experiment was performed twice.

Effects of cell-free supernatants of Lactobacillus spp. on biofilm formation of UPECS

The biofilm formation in three out of 50 UPEC strains (which were determined previously as biofilm forming strains) were observed with crystal violet staining method.The effects of lactobacilli cell-free supernatans on three biofilm positive UPEC strains were analyzed. E. coli ATCC 25922 and MRSA ATCC 43300 were used as positive controls. The strains were cultured in TSBglucose $(1 \% \mathrm{v} / \mathrm{v})$ for $24 \mathrm{~h}$ at $37{ }^{\circ} \mathrm{C}$ and diluted $1 / 50$ in fresh TSB-glucose, yielding a final concentration of approximately $10^{7} \mathrm{CFU} / \mathrm{mL}$. $100 \mu \mathrm{L}$ from bacterial suspension and $100 \mu \mathrm{L}$ from cell-free supernatants of Lactobacillus probiotic products were added to each well of a 96-well tissue culture microtiter plate, and then incubated for 24 hours at $37^{\circ} \mathrm{C}$. TSB-glucose was used as a negative control. After incubation, the waste media was gently aspirated, and the wells were washed $3 \times$ with $250 \mu \mathrm{L}$ Phosphate Buffered Saline (PBS) solution to remove any unattached bacteria and air-dried. Then, $200 \mu \mathrm{L}$ 99\% methanol was added to each well to fixate for $15 \mathrm{~min}$, then it was aspirated. Wells were stained with $200 \mu \mathrm{L}$ $0.1 \%$ crystal violet (in water) for $5 \mathrm{~min}$. Excess stain was gently rinsed off with tap water, and the plates were air-dried. The stain was resolubilized by adding $200 \mu \mathrm{L} 95 \%$ ethanol. The optical density was measured at $450 \mathrm{~nm}$. For the purposes of comparative analysis of test results, we introduced classification of adherence capabilities of tested strains into four categories $(\mathrm{OD} \leq \mathrm{ODc}$ non-adherent, $\mathrm{ODc}<\mathrm{OD} \leq 2 \mathrm{x}$ OD weakly adherent, $2 x O D c<O D \leq 4 \times$ ODc moderately adherent, 4xODc <OD strongly adherent) as described previously (Christensen et al., 1985).

\section{Statistical analysis}

Growth alterations were detected by using Kruskal-Wallis test. The effects of probiotic supernatants of Lactobacillus on biofilm formations of UPECs were determined via oneway ANOVA Tukey's multiple-comparison test. All measurements were compared to control conditions (TSB). Multiple comparisons were made at a level of $\mathrm{P}<0.05$.

\section{Results and discussions}

Effects of probiotic supernatants of Lactobacillus spp. on growth of UPECs

The direct antagonism of compounds contained in Lactobacillus cell-free supernatants against UPECs was monitored by turbidmetric method. Supernatants of all four Lactobacillus species inhibited growth of UPECs with a high rate of $99 \%$ when compared to control (TSB) (Fig. 1).

These results were found to be statistically significant $(p<0.0001)$. To satisfy our own curiosity, we analyzed the effect of neutralized $\mathrm{pH}$ supernatants on the growth of randomly selected five UPEC strains and we detected that, supernatants with pH:6.8 did not alter the growth of UPECs $(p>0.05)$.

Effects of cell-free supernatants of Lactobacillus spp. on biofilm formations of $\underline{\text { UPECS }}$

All three biofilm forming strains were classified as weakly adherent according to Christensen et al., (1985) criteria. All tested cell-free supernatants of lactobacilli were shown to inhibit biofilm formation in three UPEC strains in 24 hours significantly $(p<0.05)$ (Fig. 2). 
Globally a large number of people suffer from urinary tract infections which are mostly caused by uropathogenic E. coli (Hacker et al., 1999; Kulkarni et al., 2009; Li et al., 2010). It is well known that Lactobacillus strains have antibacterial effects with their secreted compounds such as bacteriocin or exopolycacharides and organic acids (Makino et al., 2006; Hagan and Mobley 2007; NaderMacías et al., 2008; Cadieux et al., 2009; Martín and Suárez, 2010; Stoyancheva et al., 2014). In our study we aimed to detect the inhibitory effects of four different Lactobacillus spp. cell free supernatants on growth and biofilm formation because of their widely usage in dairy products, fruit drinks, chewing gums and tablets which are available on market (Karska-Wysocki, 2010; Nigam et al., 2012).

Cadieux et al., (2009) have documented that some $L$. rhamnosus and $L$. reuteri strains could affect UPECs surface membrane traits. Delley et al., (2015) have shown that $L$. acidophilus, L. rhamnosus and L. johnsonii strains' cell free supernatants inhibited some UPEC strains. Similarly Tomas et al., (2011) have shown the growth inhibition of UPECs in the presence of $L$. acidophilus. Ocana et al., (1999) have also observed that some $L$. acidophilus strains (CRL 1259, CRL 1307, CRL 1320 and CRL 1324) inhibited the growth of E. coli, Staphylococcus aureus, Streptococcus agalactiae, Enterococcus faecalis, Klebsiella, N. gonorrhoeae and $G$. vaginalis. Terraf et al., (2017) have detected that supernatants from $L$. reuteri and $L$. rhamnosus inhibited the growth of UPEC strains. Miyazaki et al., (2010) shown that supernatants of $L$. casei subspecies and $L$. acidophilus inhibited the growth of the EAggEC TN-2 strain

Many studies have suggested that in order to prevent growth of pathogenic microorganisms that cause urogenital infections, probiotic products can be used. Some researchers suggested that antagonistic effects (bacteriostatic or bactericidal) of Lactobacillus on growth of E. coli related to the presence of organic acids that are released during growth (Axe and Bailey, 1995; DiezGonzalez and Russell, 1997). In line with previous studies we detected that, supernatants of L. acidophilus, L. plantarum, L. fermentum and L. rhamnosus supernatants inhibited growth of UPECs.

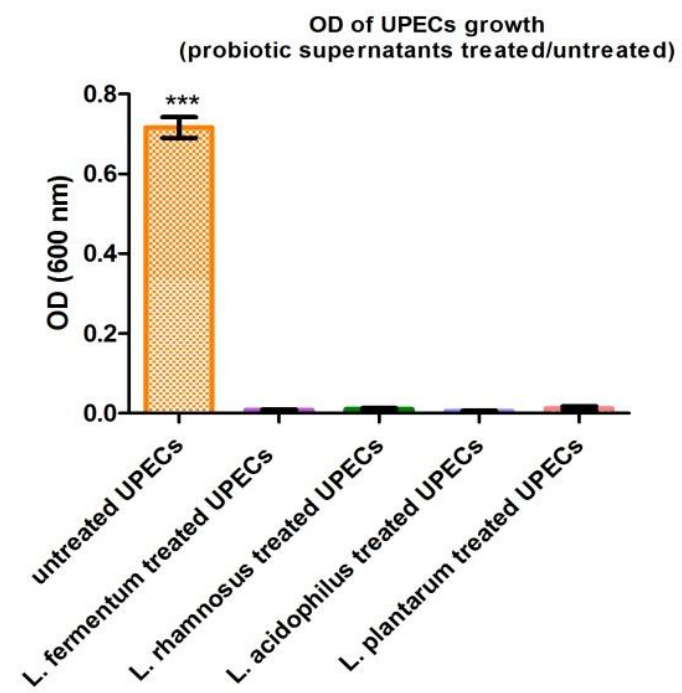

Fig. 1. Effects of different cell-free supernatants on growth in UPECs 

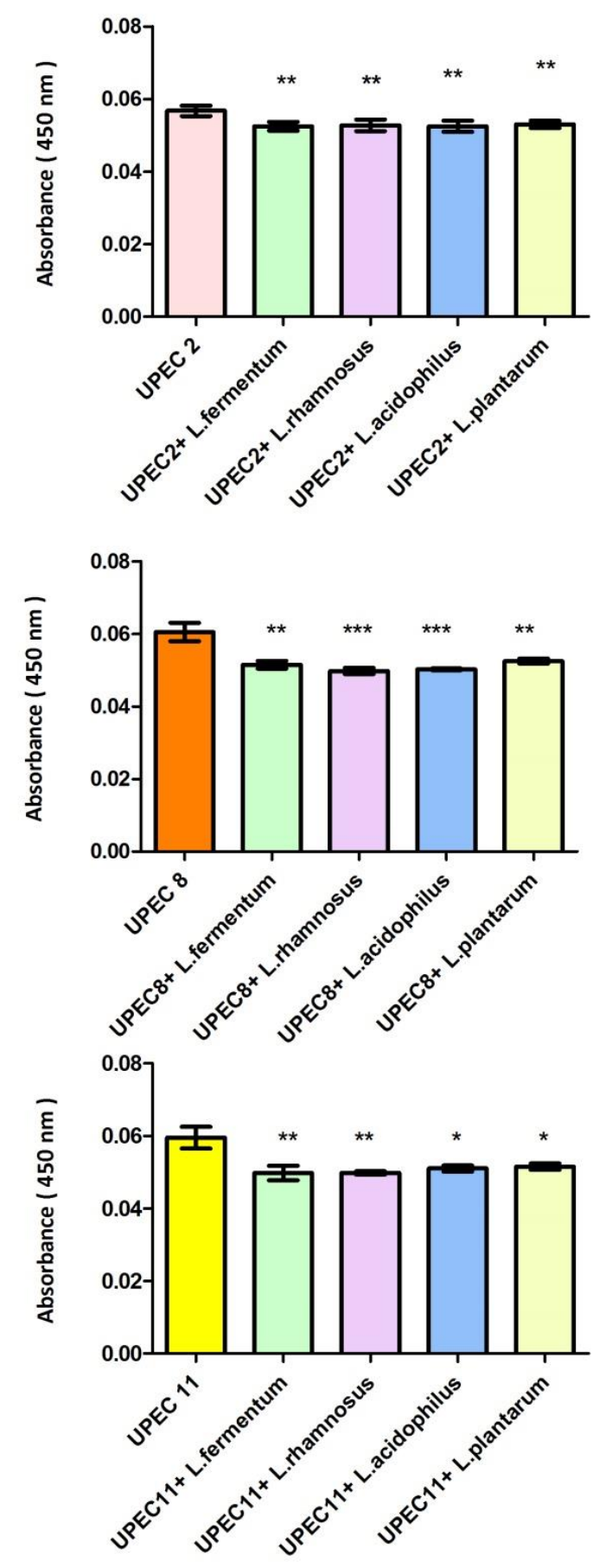

Fig. 2. Effects of different cell-free supernatants on biofilm formations in three different UPEC strains

Therefore we wanted to investigate whether the $99 \%$ of inhibition with probiotic supernatants depends on $\mathrm{pH}$ or not. Our results with a randomized selected five UPECs showed that, high level acidity leads the major inhibition on growth of pathogens. Evidence supports that the antagonist effects of
Lactobacillus may be variable depending on exposure time, test microorganism, temperature as well as $\mathrm{pH}$ (high acidity) (Ogawa et al., 2001; Lash et al., 2005; Poppi et al., 2015).

The most known anti-biofilm activity is related to exopolysaccharides in Lactobacillus supernatants (Barken et al., 2008; Kim and 
Kim., 2009; Wang et al., 2015). The first step of biofilm formation is adhesion to surface then multiplication of bacteria to compose extracellular polymeric matrix. Communication system which is known as quorum sensing (QS) plays an important role in adhesion and biofilm formation (Waters and Bassler, 2005; Bassler and Losick, 2006). QS provides cell to cell communication and it is important for bacterial survival and interactions in natural habitats. Previous studies have shown that there is a strong association between Lactobacillus supernatants and repression of the genes related with initial adhesion and chemotaxis (Balaban et al., 2007; Wang et al., 2015). It was suggested that, Lactobacilli supernatants could play role as molecules in reducing biofilm formation and quorum sensing related gene expressions (Balaban et al., 2007; Wang et al., 2015; Zamani et al., 2017). Sadri et al., (2016) have suggested that $L$. acidophilus inhibited adhesion of UPECs. Zamani et al., (2017) reported that $L$. plantarum isolated from a traditional cheese had anti-biofilm potential for Pseudomonas aeruginosa, Staphylococcus aureus and E. coli. Vacheva et al., (2012) reported that L. gasseri Lb821, L. plantarum LbS11 had anti-biofilm effects on E. coli strains. On the other hand, Miyazaki et al., (2010) reported that the supernatants of $L$. casei and L. rhamnosus stimulated biofilm formation of enteroaggregative Escherichia coli. In our study, all the tested Lactobacillus supernatants were found to inhibit biofilm formation in UPEC strains in consistency with the results of many other studies (Kim and Kim., 2009; Vacheva et al., 2012; Aminnezhad et al., 2014; Zamani et al., 2017).

\section{Conclusions}

As conclusion in our study it was shown that, the growth of 50 different clinical UPEC strains were inhibited by Lactobacillus spp. with a rate of $99 \%$. Besides, biofilm formations of three UPECs were also inhibited significantly in the presence of cell-free supernatant of four Lactobacillus strains tested. Therefore consistent with previous studies, our findings support that these four lactobacilli may be used to prevent the UTIs caused by UPEC strains, effectively.

\section{Conflict of Interest}

The authors declare that the research was conducted in the absence of any commercial or financial relationships that could be construed as a potential conflict of interest.

\section{Acknowledgments}

The authors would like to thank emeritus Prof. Dr. Özdem Anğ for critical reading of the manuscript.

\section{References}

1. Aminnezhad S, Kasra-Kermanshahi $\mathrm{R}$ (2014) Antibiofilm activity of cell-free supernatant from Lactobacillus casei in Pseudomonas aeruginosa. Feyz 18:30-7.

2. Andersen TE, Khandige S, Madelung M, Brewer J, Kolmos HJ, Møller-Jensen J (2012) Escherichia coli uropathogenesis in vitro: invasion, cellular escape, and secondary infection analyzed in a human bladder cell infection model. Infect and Immun 80(5): 1858-67.

3. Axe DD, Bailey JE (1995) Transport of lactate and acetate through the cytoplasmic membrane of Escherichia coli. Biotechnol Bioeng 47:8-19.

4. Balaban N, Cirioni O, Giacometti A, Ghiselli R, Braunstein JB, Silvestri C, Mocchegiani F, Saba V, Scalise G (2007) Treatment of Staphylococcus aureus biofilm infection by the quorum-sensing 
inhibitor RIP. Antimicrob Agents Chemother 51:2226-9.

5. Barken KB, Pamp SJ, Yang L, Gjermansen M, Bertrand JJ, Klausen M, Givskov M, Whitchurch CB, Engel JN, Tolker-Nielsen $\mathrm{T}$ (2008) Roles of type IV pili, flagellummediated motility and extracellular DNA in the formation of mature multicellular structures in Pseudomonas aeruginosa biofilms. Environ Microbiol 10:2331-43.

6. Bassler BL, Losick R (2006) "Bacterially speaking," Cell 125(2):237-246.

7. Beerepoot M, Ter Riet G, Nys S, van der Wal WM, De Borgie CA, de Reijke TM (2012) Lactobacilli versus antibiotics to prevent urinary tract infections. A randomized double-blind non-inferiority trial in postmenopausal women. Arch Intern Med 172(9):704-712.

8. Behnsen J, Deriu E, Sassone-Corsi M, Raffatellu M (2013) Probiotics: properties, examples, and specific applications. Cold Spring Harb Perspect Med 3:1-15.

9. Bower JM, Eto DS, Mulvey MA (2005) Covert operations of uropathogenic Escherichia coli within the urinary tract Traffic 6:18-31.

10. Cadieux PA1, Burton J, Devillard E, Reid G (2009) Lactobacillus by-products inhibit the growth and virulence of uropathogenic Escherichia coli. J Physiol Pharmacol 60 (Suppl 6):13-18.

11. Christensen GD, Simpson WA, Younger JJ, Baddour LM, Barrett FF, Melton DM, Beachey EH (1985) Adherence of coagulase-negative staphylococci to plastic tissue culture plates: a quantitative model for the adherence of staphylococci to medical devices. J Clin Microbiol 22:9961006.

12. Delley M, Bruttin A, Richard M, Affolter M, Rezzonico E, Brück WM (2015) In vitro activity of commercial probiotic Lactobacillus strains against uropathogenic
Escherichia coli. FEMS Microbiology Lett 362(13).

13. Diez-Gonzalez F, Russell JB (1997) The ability of Escherichia coli O157:H7 to decrease its intracellular $\mathrm{pH}$ and resist the toxicity of acetic acid. Microbiol 143:11751180

14. Freestone P (2013) Communication between bacteria and their hosts. Scientifica 2013:1-15

15. Geerlings SE, Beerepoot MA, Prins JM (2014) Prevention of recurrent urinary tract infections in women: antimicrobial and nonantimicrobial strategies. Infect Dis Clin, 28(1):135-147.

16. Guandalini S (2011) Probiotics for prevention and treatment of diarrhea. J Clin Gastroenterol 45:149-153.

17. Guarino A, Vecchio AL, Canani RB (2009) Probiotics as prevention and treatment for diarrhea. Curr Opin Gastroenterol 25(1):18-23.

18. Hacker J, Blum-Oehler G, Janke B, Nagy G, Goebel W (1999) Pathogenicity Islands of Extraintestinal Escherichia coli. In Kaper JB, Hacker J (eds) Pathogenicity Islands and Other Mobile Virulence Elements. Washington DC: ASM Press 59-76.

19. Hagan EC, Mobley HLT (2007) Uropathogenic Escherichia coli outer membrane antigens expressed during urinary tract infection. Infect Immun 75:3941-9.

20. Hunstad DA, Justice SS (2010) Intracellular lifestyles and immune evasion strategies of uropathogenic Escherichia coli. Annu Rev Microbiol 64:203-221.

21. Karska-Wysocki B, Bazo M, Smoragiewicz W (2010) Antibacterial activity of Lactobacillus acidophilus and Lactobacillus casei against methicillinresistant Staphylococcus aureus (MRSA). Microbiol Res 165(8):674-686. 
22. Kim Y, Kim SH (2009) Released exopolysaccharide (r-EPS) produced from probiotic bacteria reduce biofilm formation of enterohemorrhagic Escherichia coli O157: H7. Biochem Biophys Res Commun 379:324-9.

23. Kulkarni R, Dhakal BK, Slechta ES, Kurtz Z, Mulvey MA, Thanassi DG (2009) Roles of putative type II secretion and type IV pilus systems in the virulence of uropathogenic Escherichia coli. PLoS One 4(3).

24. Kulkarni R, Dhakal BK, Slechta ES, Kurtz Z, Mulvey MA, Thaassi DG (2009) Roles of putative type II secretion and type IV pilus systems in the virulence of uropathogenic Escherichia coli. PLoS ONE $4: 1-9$.

25. Lash BW, Mysliwiec TH, Gourama H, Mysliwiec TH (2005) Detection and partial characterization of a broad-range bacteriocin produced by Lactobacillus plantarum (ATCC 8014). Food Microbiol 22:199-204.

26. Lee JH, Subhadra B, Son YJ, Kim DH, Park HS, Kim JM, Koo SH, Oh MH, Kim HJ, Choi CH (2016) Phylogenetic group distributions, virulence factors and antimicrobial resistance properties of uropathogenic Escherichia coli strains isolated from patients with urinary tract infections in South Korea. Lett App Microbiol 62(1):84-90.

27. Li D, Liu B, Chen M, Guo D, Guo X, Liu F, Feng L, Wang L (2010) A multiplex PCR method to detect 14 Escherichia coli serogroups associated with urinary tract infections. J Microbiol Methods 82:71-7.

28. Makino S, Ikegami S, Kano H, Sashihara T, Sugano H, Horiuchi H, Saito T, Oda M (2006) Immunomodulatory effects of polysaccharides produced by Lactobacillus delbrueckii ssp. bulgaricus OLL1073R-1. J Dairy Sci 89:2873-81.
29. Mandal P, Kapil A, Goswami K, Das B, Dwivedi SN (2001) Uropathogenic Escherichia coli causing urinary tract infections. Indian J Med Res 114:207-11.

30. Martín R, Suárez JE (2010) Biosynthesis and degradation of $\mathrm{H}_{2} \mathrm{O}_{2}$ by vaginal lactobacilli. Appl Environ Microbiol 76:400-405.

31. Miyazaki J, Ba-Thein W, Kumao T, Obata Yasuoka M, Akaza H, Hayshi H (2002) Type 1, $\mathrm{P}$ and $\mathrm{S}$ fimbriae, and afimbrial adhesin I are not essential for uropathogenic Escherichia coli to adhere to and invade bladder epithelial cells. FEMS Immunol Med Microbiol 25:23-6.

32. Miyazaki Y, Yokota H, Takahashi H, Fukuda M, Kawakami H, Kamiya S, Hanawa $T$ (2010) Effect of probiotic bacterial strains of Lactobacillus, Bifidobacterium, and Enterococcus on enteroaggregative Escherichia coli. J Infect Chemother 16(1):10-18.

33. Morais MBD, Jacob CMA (2006) The role of probiotics and prebiotics in pediatric practice. J de Pediat 82(5):189-97.

34. Morelli L, Zonenenschain D, Del Piano M, Cognein P (2004) Utilization of the intestinal tract as a delivery system for urogenital probiotics. J Clin Gastroenterol 38:107-110.

35. Nader-Macías MEF, Silva de Ruiz C, Ocaña VS, Juárez Tomás MS (2008) Advances in the knowledge and clinical applications of lactic acid bacteria as probiotics in the urogenital tract. Curr Women's Health Rev 4:240-257.

36. Nigam A, Kumar A, Madhusuda HV, Bhola N (2012) In-vitro Screening of antibacterial activity of lactic acid bacteria against common enteric pathogens Astha Nigam, Madhusudan HV, and Neelam Bhola Departmaent of Microbiology, CloneGen Biotechnology Ltd. J Biomed Sci 4(2):1-5. 
37. Ocana VS, Bru E, de Ruiz Holgado AA Nader-Macias ME (1999) Surface characteristics of lactobacilli isolated from human vagina. J Gen Appl Microbiol 45:203-212.

38. Ogawa M, Shimizu K, Nomoto K, Tanaka R, Hamabata T, Yamasaki S, Takeda T, Takeda Y (2001) Inhibition of in vitro growth of Shiga toxin-producing Escherichia coli $\mathrm{O} 157: \mathrm{H7}$ by probiotic bacteria Lactobacillus strains due to production of latic acid. Int $\mathrm{J}$ Food Microbiol 68:135-140.

39. Poppi LB, Rivaldi JD, CoutinhoTS, Astolfi-Ferreira CS, Ferreira AJP, Mancilha IM (2015) Effect of Lactobacillus sp. isolates supernatant on Escherichia coli O157: H7 enhances the role of organic acids production as a factor for pathogen control. Pesquisa Veterinária Brasileira 35(4):353-359.

40. Ruiz J, Simon K, Horcajada JP, Velasco M, Barranco M, Roig G, Moreno-Martínez A, Martínez JA, Jiménez de Anta T, Mensa J, Vila J (2002) Differences in virulence factors among clinical isolates of Escherichia coli causing cystitis and pyelonephritis in women and prostatitis in men. J of Clin Microbiol 40:12:4445-49.

41. Saavedra J (2000) Probiotics and infectious diarrhea. Am J Gastroenterol 95(1) :16-18.

42. Sabaté M, Moreno E, Pérez T, Andreu A, Prats G (2006) Pathogenicity island markers in commensal and uropathogenic Escherichia coli isolates. Clin Microbiol Infect 12:880

43. Sadri M, Arab Soleimani N, Forghanifard MM (2016) The study of Antimicrobial and Anti-adhesive effect of Probiotic Lactobacilli on Uropathogenic Escherichia coli (UPEC). Biol J Microorganism 5:15970.

44. Segarra-Newnham M (2007) Probiotics for Clostridium difficile-associated diarrhea: focus on Lactobacillus rhamnosus GG and Saccharomyces boulardii. Ann Pharmacother 41(7-8):1212-21.

45. Servin AL (2004) Antagonistic activities of lactobacilli and bifidobacteria against microbial pathogens. FEMS Microbiol Rev 28(4):405-440.

46. Sivick K E, Mobley H L (2010) Waging war against uropathogenic Escherichia coli: winning back the urinary tract. Infect Immun 78(2):568-585.

47. Stoyancheva G, Marzotto M, Dellaglio F, Torriani S (2014) Bacteriocin production and gene sequencing analysis from vaginal Lactobacillus strains. Arch Microbiol 196:645-653

48. Terraf MCL, Tomás MSJ, Rault L, Le Loir Y, Even S, Nader-Macías MEF (2017) In vitro effect of vaginal lactobacilli on the growth and adhesion abilities of uropathogenic Escherichia coli. Arch Microbiol 199(5):767-774.

49. Tomas J MS, Ocaña VS, Wiese B, NaderMacías ME (2003) Growth and lactic acid production by vaginal Lactobacillus acidophilus CRL 1259, and inhibition of uropathogenic Escherichia coli. J Med Microbiol 52(12):1117-1124.

50. Tomás J MS, Saralegui Duhart CI, De Gregorio PR, Vera Pingitore E, NaderMacías ME (2011) Urogenital pathogen inhibition and compatibility between vaginal Lactobacillus strains to be considered as probiotic candidates. Eur $\mathbf{J}$ Obstet Gynecol Reprod Biol 159:399-406.

51. Turroni F, Ventura M, Butto LF. et al. (2014) Molecular dialogue between the human gut microbiota and the host: a Lactobacillus and Bifidobacterium perspective. Cell Mol Life Sci 71:183-203. 52. Uzun $\mathrm{C}$, Oncül $\mathrm{O}$, Gümüş $\mathrm{D}$, Alan $\mathrm{S}$, Dayioğlu N, Küçüker MA (2015) Virulence genes and antibiotic susceptibilities of 
uropathogenic E. coli strains. Clin Lab 61(8):941-950.

53. Vacheva A, Georgieva R, Danova S, Mihova R, Marhova M, Kostadinova S, Stoitsova S (2012) Modulation of Escherichia coli biofilm growth by cell-free spent cultures from lactobacilli. Open Life Sci 7(2):219-229.

54. Wagner RD, Johnson SJ (2012) Probiotic lactobacillus and estrogen effects on vaginal epithelial gene expression responses to Candida albicans. J Biomed Sci 19(1):58.

55. Wang J, Zhao X, Yang Y, Zhao A, Yang Z (2015) Characterization and bioactivities of an exopolysaccharide produced by Lactobacillus plantarum YW32. Int J Biol Macromol 74:119-26.

56. Waters CM, Bassler BL (2005) "Quorum sensing: cell-to-cell communication in bacteria”. Annu Rev Cell Dev Biol 21:319346.

57. Wu CC, Lin CT, Wu CY, Peng WS, Lee MJ, Tsai YC (2015) Inhibitory effect of Lactobacillus salivarius on Streptococcus mutans biofilm formation. Mol Oral Microbiol 30(1):16-26.

58. Yamamoto S (2007) Molecular epidemiology of Escherichia coli. J Infect Chemother 13:68-73.

59. Zamani H, Rahbar S, Garakoui SR, Afsah Sahebi A, Jafari H (2017) Antibiofilm potential of Lactobacillus plantarum spp. cell free supernatant (CFS) against multidrug resistant bacterial pathogens. Pharma Biomed Res 3(2):39-44.

60. ***FAO/WHO (2001). Health and Nutritional Properties of Probiotics in Food Including Powder Milk with Live Lactic Acid Bacteria. Cordoba, Argentina: WHO. 